\title{
Efecto del Lactobacilius acidophilus y Lactobacilius bifidus como probiótico comercial en la dieta del hámster dorado (Mesocricetus auratus)
}

\section{Effect of Lactobacilius acidophilus and Lactobacilius bifidus as probiotic}

\section{trade in the diet of the golden hamster (Mesocricetus auratus)}

\author{
Arias A. A. ${ }^{1}$, Hernández M. C. ${ }^{2}$, Corredor J. R. ${ }^{3}$ \\ ${ }^{1} \mathrm{MVZ}$, Universidad de los Llanos; ${ }^{2} \mathrm{MVZ}$. Esp. Docente Universidad de los Llanos y \\ ${ }^{3}$ MVZ. MSc. Docente Asociado Universidad de los Llanos \\ andres.arias@unillanos.edu.co
}

Recibido 09 de Noviembre de 2009, aprobado 01 de Diciembre 2010

\section{RESUMEN}

Los probióticos han sido considerados por muchos autores como microorganismos y/o sustancias que afectan la flora intestinal por distintos mecanismos de tal manera que sus efectos benéficos no solo se han reportado en tracto gastrointestinal, también en el respiratorio y urogenital. El objetivo del presente trabajo es evaluar, crecimiento y ganancia de peso con el suministro de un coctel probiótico que contenía (Lactobacilius acidophilus y Lactobacilius bifidus), de uso comercial en el hámster dorado para el cual se obtuvieron 20 animales experimentales con una vida en promedio de 8 a 15 días, los cuales se dividieron en dos grupos experimentales, grupo control (GC) y experimental (GM) en cual tuvo una duración de 3 semanas. Los resultados obtenidos muestran que el suministro de probiótico afecto el peso y el crecimiento de los hámsteres durante su desarrollo a la adultez.

Palabras claves: Hámster dorado, probióticos, Lactobacilius acidophilus, Lactobacilius bifidus.

\section{ABSTRACT}

Probiotics have been considered by many authors as microorganisms and/or substances which affect intestinal flora by different mechanisms so that their 
beneficial effects have been reported not only in the gastrointestinal tract, including in the respiratory and urogenital. The aim of this study is to assess growth and weight gain with the provision of a probiotic cocktail containing (Lactobacilius acidophilus and Lactobacilius bifidus) of commercial use in the golden hamster which were obtained for 20 experimental animals with an average life 8 to 15 days, which were divided into two experimental groups, control group (GC) and experimental (GM) which lasted for eight weeks. The results show that the supplies of probiotic affect weight and growth of the hamsters during development to adulthood.

Keywords: Golden hamster, probiotics, Lactobacilius acidophilus, Lactobacilius bifidus.

\section{INTRODUCCIÓN}

En la actualidad la cría intensiva animal ha aumentado considerablemente, por lo que tienden a acrecentarse los problemas en la salud de estos, afectando su fisiología y como consecuencia efectos nocivos sobre la economía. Durante toda la historia se ha investigado en busca de aditivos que mejoren el bienestar animal y el comportamiento productivo, estableciéndose por primera vez en 1965 el término de probiótico (Barron et al., 2006). En décadas pasadas el método más común para prevenir enfermedades y aumentar la eficiencia alimentaria, fue el uso de antibióticos como aditivo alimentario, pero se ha comprobado que tienen influencias negativas en la eubiosis del sistema gastrointestinal, además de que dan lugar a la aparición de la resistencia bacteriana a estos fármacos y a su presencia residual en las carnes, huevos, leche y otros productos de origen animal, es por ello que se han introducido los probióticos como una solución alternativa promisoria (Vega et al., 2005; Mombeli y Gismondo, 2000).

Los problemas entéricos, especialmente en lechones y en muchos otros mamíferos de interés zootécnico, son una de las principales causas de pérdidas económicas en la industria. La totalidad de las granjas porcinas utiliza 
antibióticos de manera terapéutica y subterapéutica para controlar estos problemas, pero se debe incidir en la búsqueda de otros aditivos, que ofrezcan mejores o similares beneficios que los antibióticos y que a su vez no sean perjudiciales para los animales ni el hombre (Lázaro et al., 2005).

Las principales formas de control de enfermedades entéricas se basan en el uso de antibióticos vía alimento; no obstante, su uso prolongado puede generar resistencia en cierto tipo de bacterias patógenas. Esto no sólo reduce el número de antimicrobianos disponibles en la industria para el control de infecciones bacterianas, sino que esta resistencia incrementa el riesgo para la salud humana (Lázaro et al., 2005, Vallejo y Toro 2002)

Los probióticos han sido señalados como posibles reemplazos de los antibióticos. Estos han sido definidos como microorganismos vivos que ejercen un efecto benéfico para el tracto intestinal del hospedero, manteniendo y reforzando los mecanismos de defensa ante patógenos sin perturbar las funciones fisiológicas y bioquímicas normales (Lázaro et al., 2005, Puertollano et al., 2008, Miranda, 2008).

Debido a los beneficios que potencialmente se pueden derivar como resultado de la manipulación de la flora intestinal en términos prevención de infección gastrointestinal, cáncer y enfermedad cardiovascular, supresión de bacterias nocivas y promoción del desarrollo de bacterias benéficas, recientemente se ha generado un gran interés en el desarrollo de productos que permitan la posibilidad de modificar la flora intestinal por medios dietéticos: el uso de probióticos y prebióticos. El valor de estos radica en su uso como agentes profilácticos y su incorporación en alimentos es el mecanismo más adecuado para asegurar la presencia de bacterias benéficas en el intestino (Escalante, 2001).

Desde un punto de vista farmacológico, es de vital importancia señalar que los pro y prebióticos nunca podrán competir con los antimicrobianos como agentes terapéuticos, pero pueden reducir la incidencia de trastornos intestinales, 
entre ellos, los que frecuentemente son causados por el uso de antibióticos. Esta actividad se puede ver favorecida si estos compuestos son incorporados de manera rutinaria en la dieta normal de un individuo (Escalante, 2001, Puertollano et al., 2008). Sin embargo, los beneficios que ofrecen los probióticos se pueden categorizar en nutricionales o beneficios terapéuticos. Dentro de lo nutricional se encuentra su papel para aumentar la biodisponibilidad de calcio, zinc, hierro, magnesio, cobre, fosforo. A nivel terapéutico, se pueden utilizar para tratamientos de desórdenes intestinales, hipercolesterolemia, supresión de enzimas procarcinógenas e inmunomodulación, entre otros (Iñiguez y Acedo 2006, Puertollano et al., 2008, Martínez y Mesa del Castillo, 2005, Barron et al., 2006)

Los probióticos son utilizados para reforzar la capacidad de defensa natural de la microflora comensal del intestino. Los mecanismos de acción propuestos son variados e involucran los de adhesión donde tienen lugar interacciones de tipo específico y no especifico que posiblemente se ven afectados por la presencia de sales biliares. Al parecer los receptores intestinales (carbohidratos) juegan un papel muy importante, como ya se ha observado en algunos estudios. Sin embargo, esa es un área poco explorada (Iñiguez y Acedo, 2006; Miranda, 2008) no obstante, se requieren más investigaciones rigurosas para comprobar si en la mayoría de las bacterias que ofrecen beneficios a la salud humana y/o animal, están presentes las mismas interacciones al llegar al tracto intestinal o si esto es una característica intrínseca de cada cepa probiótica (Iñiguez y Acedo, 2006).

El uso de probióticos, principalmente de Lactobacillus y Bifidobacterium, ha sido estudiado en ensayos clínicos, siendo las principales enfermedades tratadas la diarrea aguda infantil, la diarrea asociada a antibióticos entre otras alteraciones gastrointestinales. (Vallejo y Toro, 2002; Martínez y Mesa del Castillo, 2005; Barron et al., 2006).

Un mecanismo de acción que se ha detectado en las bacterias lácticas del género lactobacillus y que muy poco se ha investigado es la capacidad para 
desconjugar ácidos biliares mediante un sistema enzimático que permite la transformación de sales biliares a formas no conjugadas, a las cuales se le atribuyen un mayor efecto inhibidor sobre algunos gérmenes. Esta acción tiene también relación con un incremento en el catabolismo del colesterol, debido al aumento en la secreción de sales biliares (Oropeza, 1998; Puertollano et al., 2008, Martínez y Mesa del Castillo, 2005).

Actualmente la información que se dispone sobre la actividad hipocolesterolémica de las cepas se centra en estudios in vitro, por lo que hay que esperar posteriores estudios que confirmen realmente que el consumo regular de ciertos microorganismos, entre otros beneficios, produce una disminución de los niveles de colesterol plasmático y que fracciones de este disminuye; si todas, sólo LDL ("colesterol malo") o sólo HDL ("colesterol bueno") (St-Onge et al., 2000). Otros reportes muestran que dietas ricas en probióticos generan un aumento de la respuesta inmune innata, aumento en la expresión de receptores del complemento y de moléculas de adhesión en neutrófilos y monocitos y un incremento de interleukina 10 en los linfocitos de la circulación periférica. Lo anterior llevaría al desarrollo de una respuesta inmune que evitaría eventos inflamatorios alérgicos, probablemente mediada por la estimulación de linfocitos $T$ tipo 3 (TH3), importantes en la secreción de citoquinas antiinflamatorias (Vallejo y Toro, 2002).

\section{METODOLOGÍA}

Localización: El proyecto se realizó en la Universidad de Llanos a una temperatura ambiente que oscila entre los $24-34^{\circ} \mathrm{C}$ y una altitud de 410 m.s.n.m. Se utilizaron 24 animales, clínicamente sanos, con una edad promedio de 8-15 días, los cuales fueron divididos en dos grupos experimentales al azar, y alimentados ad libitum con alimento comercial (concentrado de cachorro) y a libre disponibilidad de agua. 
Diseño experimental: En el presente trabajo se suministró probiótico $L$. acidophilus y $L$. bifidus durante 3 semanas en hámster Mesocricetus auratus, con el fin de estimular la absorción de nutrientes. Se sometieron a un periodo de adaptación de 10 días Una vez cumplido el periodo de adaptación se dividieron en dos grupos al azar, uno llamado grupo control (GC) el cual tuvo 10 animales y otro llamado grupo experimental (GM), también de 10 animales, fue suplementado con $1 \mathrm{~g}$ de probiótico diario. Se realizó un análisis proximal al concentrado con el fin de establecer su calidad nutricional, posteriormente se tomaron muestras de excretas a los dos grupos para determinar el grado de absorción del alimento suministrado también con análisis proximal a la primera, segunda y tercera semana de iniciado el tratamiento. Las jaulas permanecieron unidas para evitar que factores como: la temperatura, humedad, iluminación, estrés, rayos UV entre otros, incidieran sobre los resultados.

Toma de muestras: Los animales experimentales fueron pesados al inicio del tratamiento, este peso fue lo más uniforme posible para evitar la variación en los datos al momento de discusión de los resultados. Se realizó una medición de talla midiendo desde el inicio de la nariz hasta el final de la cola al inicio del tratamiento y cada semana una vez iniciado el tratamiento.

\section{RESULTADOS Y DISCUSIÓN}

El alimento suministrado a los animales experimentales tiene aporte importante de proteína grasa y ceniza con un muy buen porcentaje de materia seca, sin embargo, el porcentaje de grasa está muy elevado lo que no correspondería con una dieta balanceada. La dieta suministrada fue concentrado para caninos cachorros ya que en un principio se suministró semilla para hámster pero debido a que los animales eran muy selectivos y no todos tenían predilección por las mismas semillas era muy difícil estimar que semillas eran las de mayor consumo y al momento de realizar el análisis nutricional de los alimentos, se tomó muestra de todas las semillas lo que nos podría a llevar datos erróneos al momento de llevar a 
cabo los análisis respectivos, de esta manera se decidió estimar una dieta la cual tuviera balanceados sus nutrientes y por indagación con algunos criadores los cuales aportaron una alternativa de alimento (Figura 1).

La Figura 2 muestra la variación en la ganancia de peso, siendo mayor la del grupo GMS con relación al grupo GCJ debido a una posible mayor absorción, ya que las bacterias contenidas en los probióticos dan origen a otras sustancias como enzimas (amilasas y proteasas) que conducen a una metabolización diferente del sustrato y podrían influir en una mejor absorción de sustancias beneficiosas para el organismo según la etapa de vida (Figuras 4 y $5)$.

Durante las tres primeras semanas del proyecto la absorción de proteína es más elevada puesto que el organismo está en desarrollo y requiere de mayores niveles de proteína para un óptimo crecimiento. En la Figura 4 se observa como los probióticos tiene un efecto benéfico al mejorar el metabolismo y aumentar la absorción de la proteína aportando una mayor disponibilidad de este factor necesario para el crecimiento, por ende, el grupo GMS obtuvo niveles de peso y talla más elevados que el grupo GCJ (Figuras 2 y 3 ).

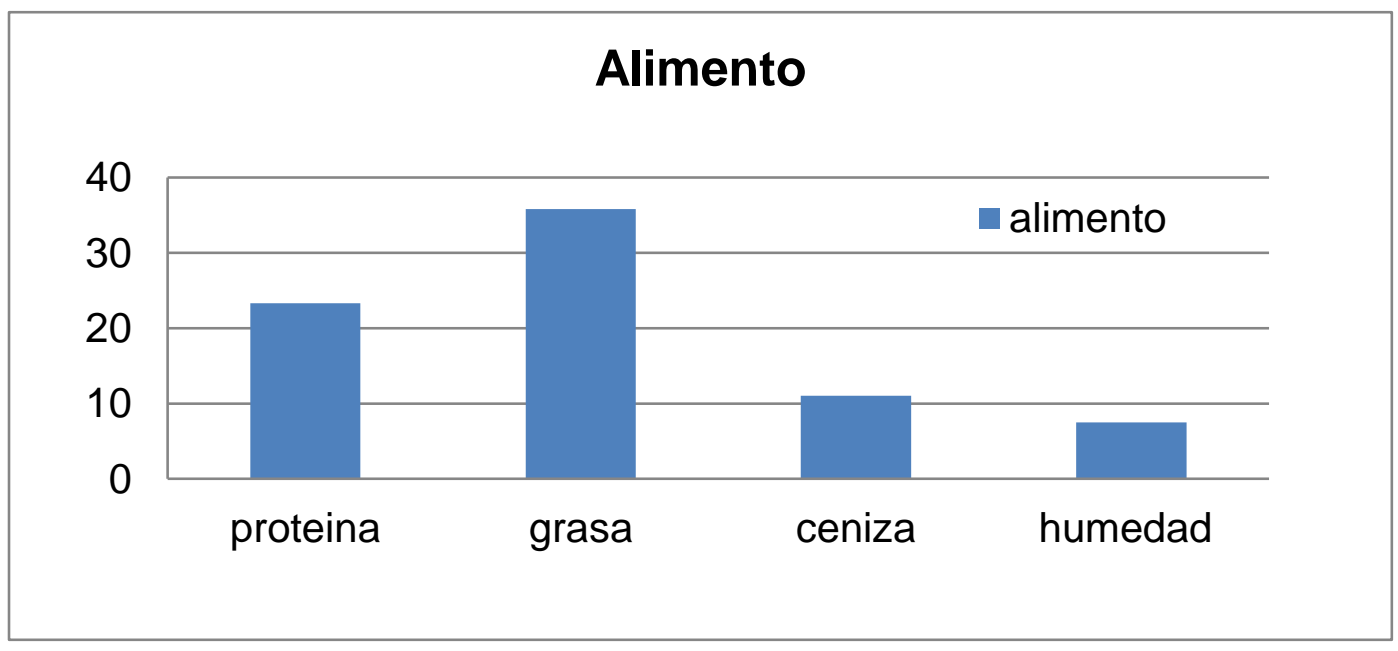

Figura 1. Análisis proximal del alimento suministrado a los Grupos experimentales 


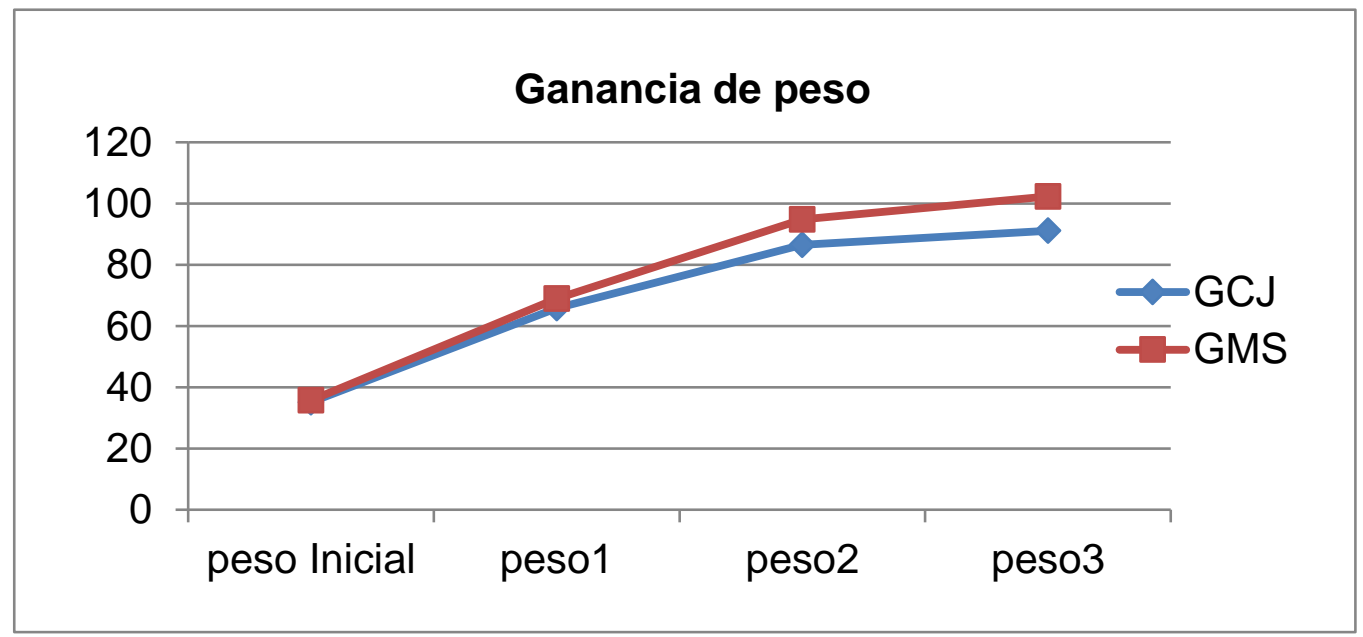

Figura 2. Ganancia de peso respectiva en cada grupo

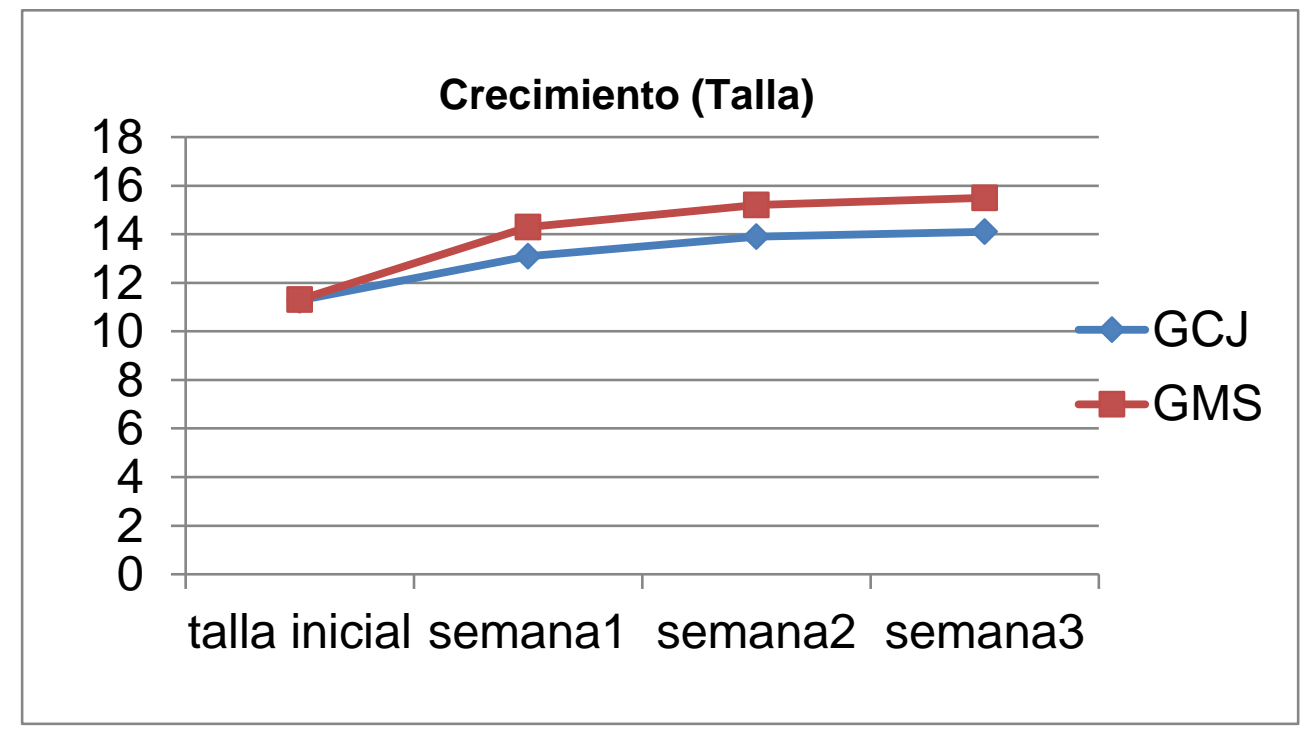

Figura 3. Ganancia de talla de los grupos experimentales

Los niveles elevados de grasa en las heces del grupo GMS (Figura 5) pueden ser debido a que los probióticos poseen enzimas que aumentan la actividad de las hidrolasas de las sales biliares ayudando a que el colesterol sea eliminado por medio de la inhibición por síntesis de colesterol, sin embargo, no se encontró literatura que reafirme este postulado.

La alta poblaciones de bacterias acidófilas hicieron que aumentara el número de células caliciformes de las criptas Lieberkuhn y al mismo tiempo provocaron un 
aumento de tamaño en los linfocitos epiteliales que se ubican en la base de las vellosidades intestinales, lo cual se traduce en una mayor sensibilización.

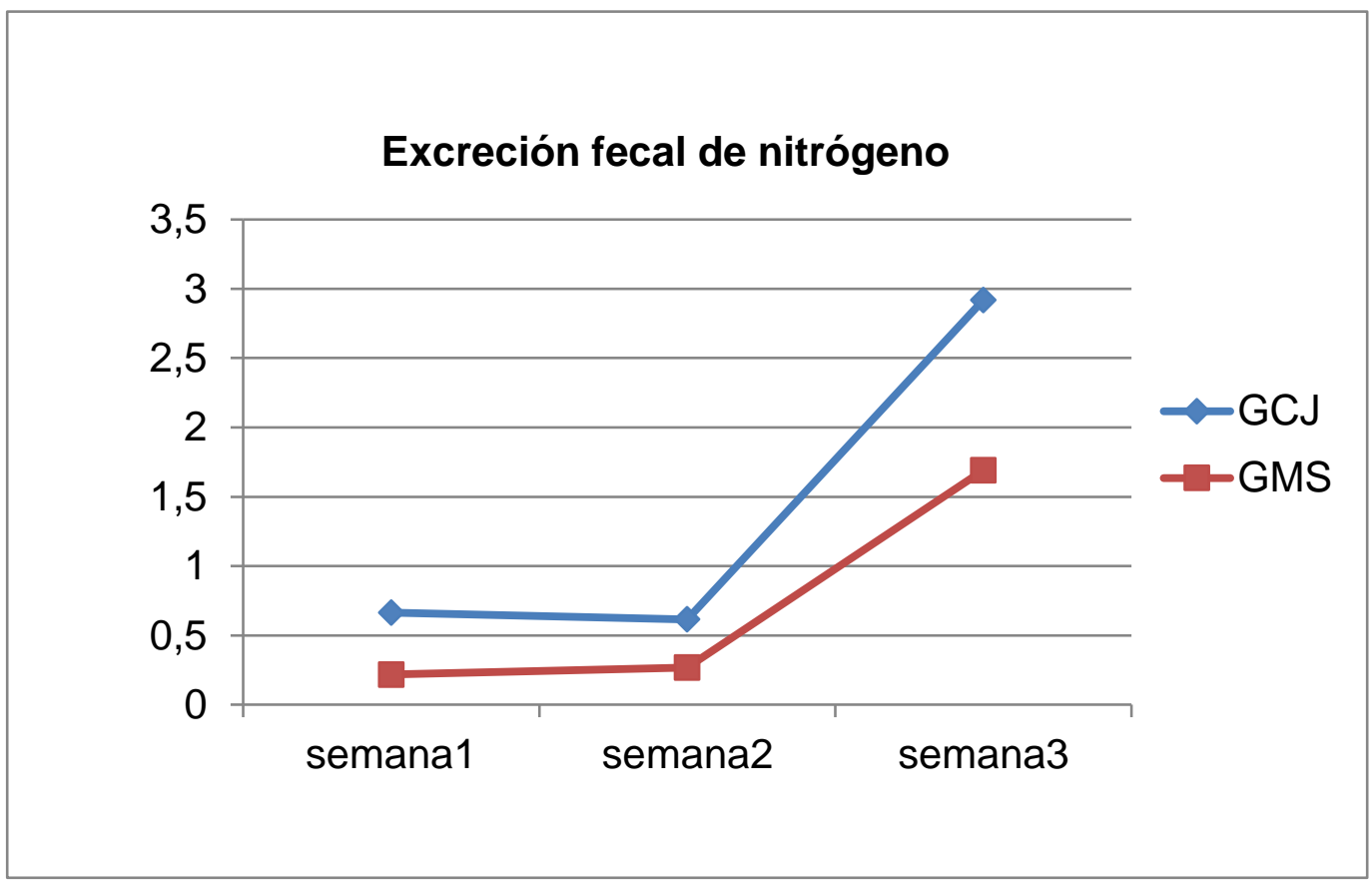

Figura 4. Nivel de excreción de nitrógeno por el animal.

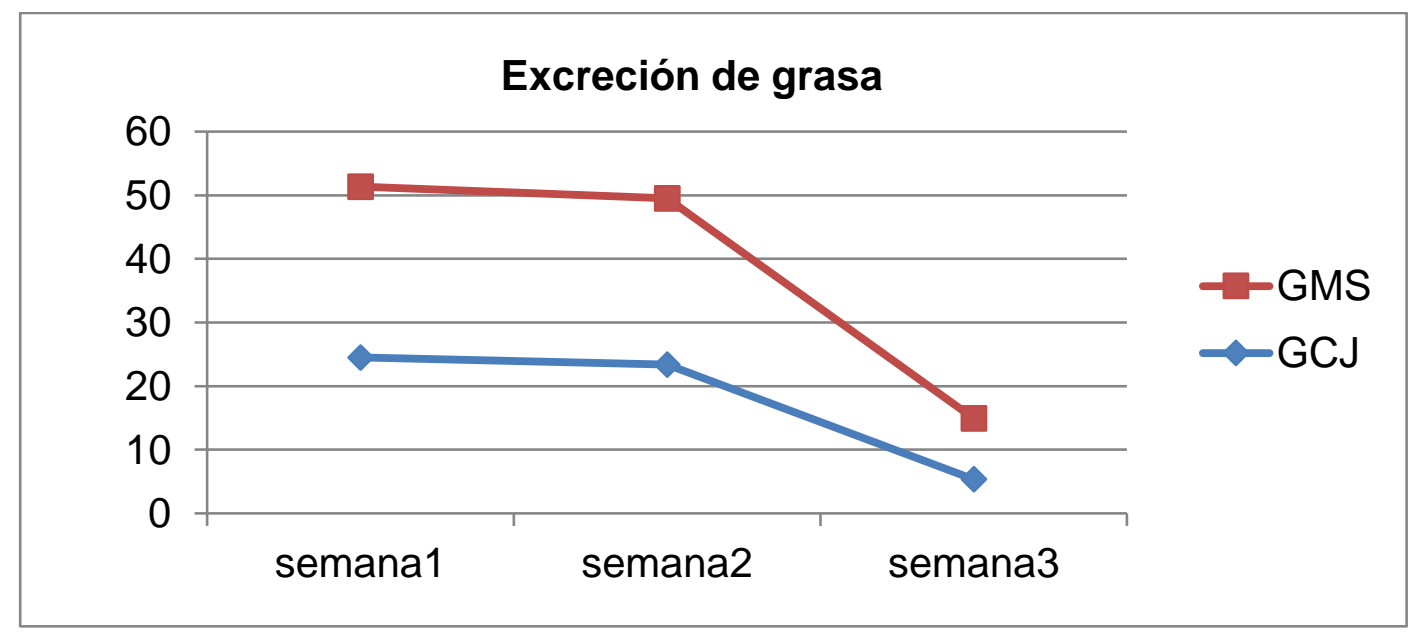

Figura 5. Nivel de excreción de grasa fecal en cada grupo experimental

En la última toma de nuestras se observa que la excreción de proteína se aumenta, esto puede ser causado debido a que los animales están alcanzando la etapa adulta y sus requerimientos de proteína son más bajos mientras que la 
absorción de grasa aumenta puesto que en el estado adulto la prioridad es el requerimiento de energía en donde el probiótico puede controlar los niveles de colesterol absorbido evitando problemas de obesidad en los animales de compañía.

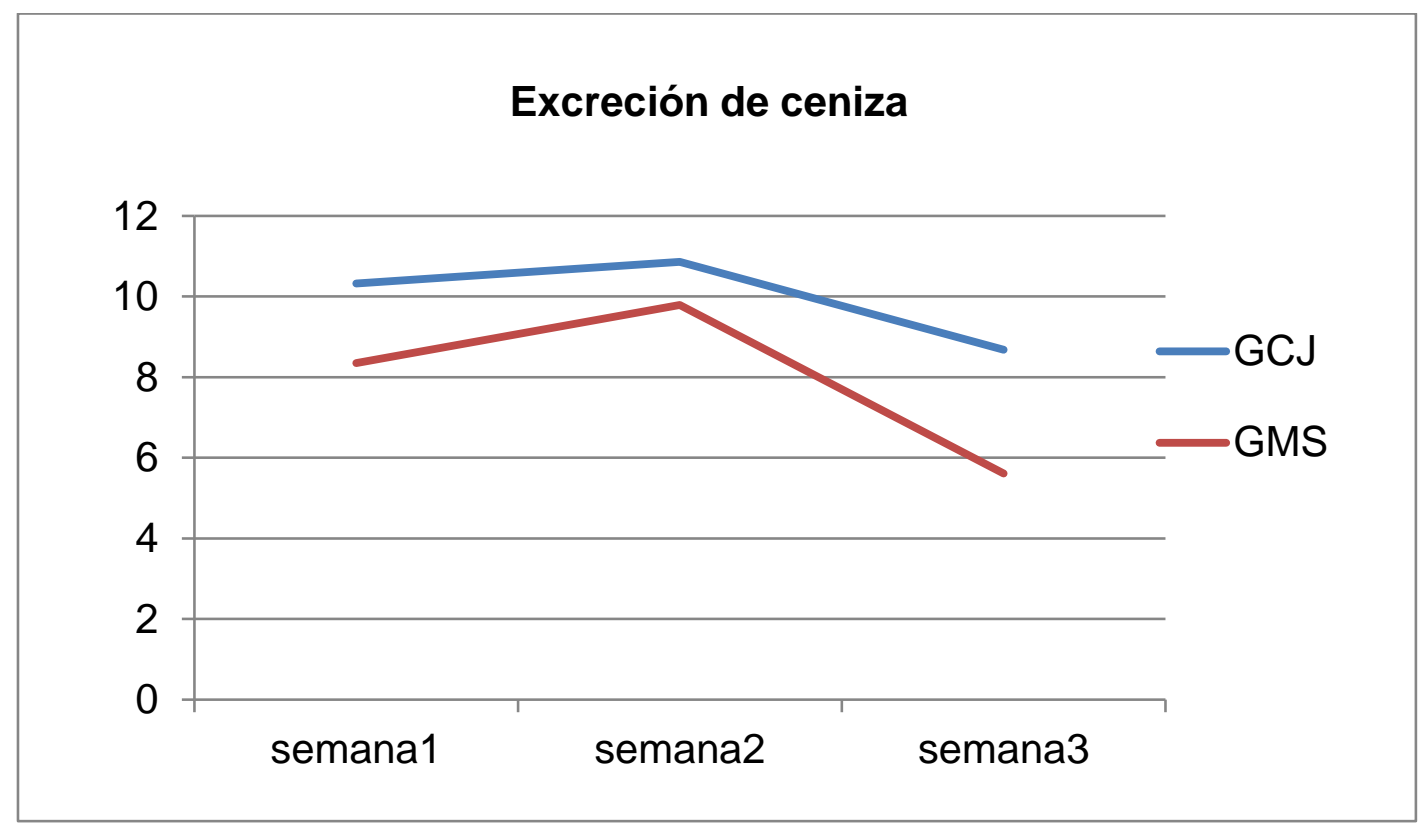

Figura 6. Nivel de ceniza excretada en las heces de cada grupo experimental

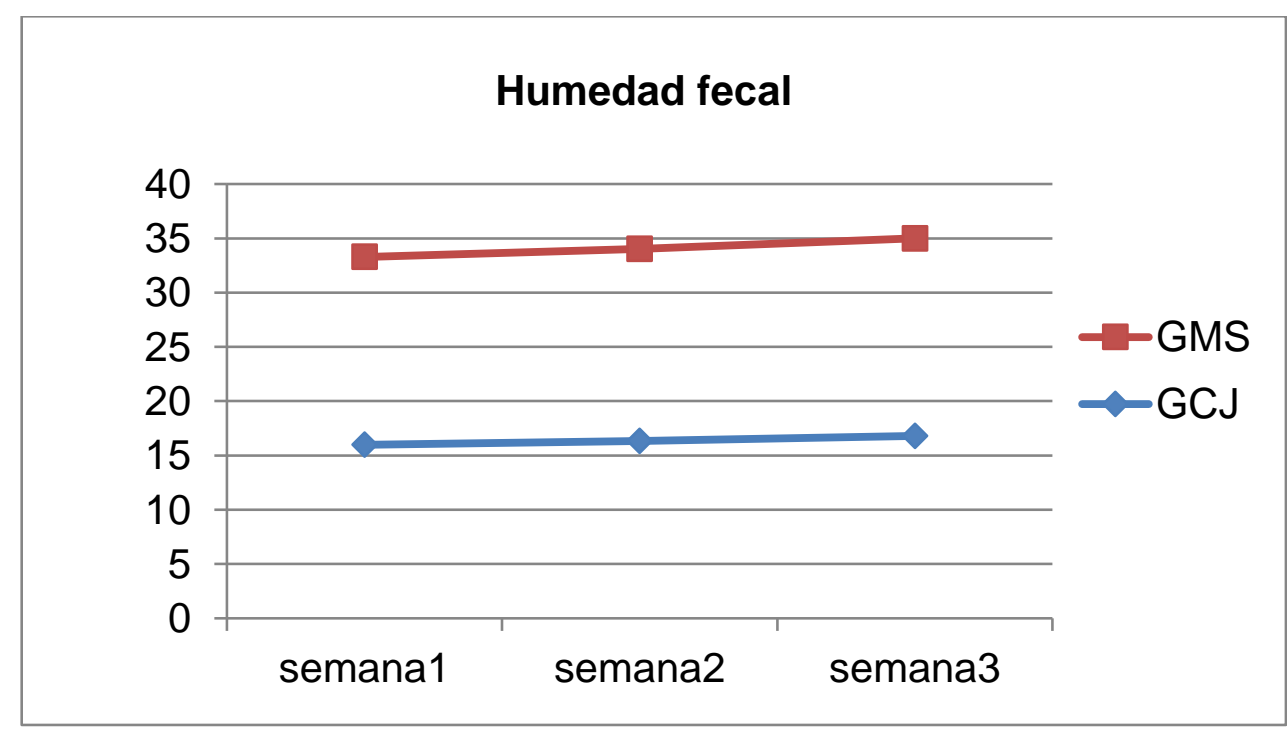

Figura 7. Nivel de humedad en las heces de cada grupo experimental 
Se debe resaltar que el probiótico utilizado fue de uso comercial en donde la vida media de las bacterias en la luz del intestino es muy corta lo que obliga a realizar un suministro diario. Estos probióticos comerciales hasta ahora usados por la industria han generado muy buenos resultados, si se recuerda el interés por los probióticos nació por consumo de leche fermentadas lo que en otro tipo de condiciones simplemente bacterias propias de esta leches ya son benéficas para el ser humano y por supuesto para los animales sin llegar a un aislamiento de estas del propio espécimen, claro está que el aislamiento asegura una mejor eficiencia y una permanencia mayor que cualquier otro microorganismo de uso comercial, sin embargo se seguirán usando probióticos comerciales debido que no hay trabajos que aíslen y comercialicen probióticos de especies animales.

Debido a que las cepas probióticas generan microambientes intestinales ácidos debido a su producción de ácido láctico este ambiente puede llegar a generar irritaciones a nivel epitelial en zonas localizadas con la subsiguiente activación del sistema entérico el cual modula los movimientos y secreciones intestinales, de esta manera al estimularse los movimientos intestinales generados por estos ambientes ácidos, el área de contacto con los alimentos se incrementa lo que facilita la digestión intraluminal y un peristaltismo más adecuado mejorando el tránsito intestinal, también las secreciones se ven alteradas incrementándose la producción de moco por las células caliciformes y demás secreciones como las de las células caliciformes, que median la protección del intestino y también facilitan la formación de masas fecales agrupando pequeños residuos fecales a lo largo de su tránsito por el colon, también facilita la adherencia de las partículas a digerir y su deslizamiento en el proceso digestivo estimulando así la limpieza del tracto en todo el proceso digestivo y este incremento en su producción estimula aún más el sistema entérico, de esta manera se puede inferir que este microambiente acido mejora las funciones protectoras del intestino limpieza mucociliar mejora el aporte de agua a las heces brindando una mejor consistencia y regula el peristaltismo 
evitando así en gran medida trastornos digestivos relacionados con el tránsito intestinal.

La producción de ácido láctico proveniente de los probióticos y otros metabolitos que generan el descenso del pH intestinal y que en las partes altas de las vías digestivas intestinales disparan la secreción de secretina para así de esta manera estabilizar el $\mathrm{pH}$ intestinal y poder llevarlo incluso un poco alcalino, y de esta manera que las enzimas pancreáticas puedan ejercer su acción, tal vez la permanente producción de ácido láctico y otros metabolitos que generen un descenso constante del $\mathrm{pH}$ active estos mecanismo que a su vez permiten una mayor actividad enzimática por parte del páncreas que puede ser debido a una estimulación continua durante el proceso digestivo, también esta estimulación de secretina al inhibir la secreción gástrica y el vaciamiento gástrico permita un mayor tiempo de los alimentos en el tubo digestivo favoreciendo su digestión, de esta manera es posible que se vea incrementada la absorción de proteína como se vio en el grupo GMS, la excreción de grasa que presentaron los grupos puede deberse también a que su dieta presentó niveles altos de este elemento por consiguiente su eliminación, pero se vio un incremento en el grupo GMS, lo cual puede deberse a que la lipasa pancreática es más inestable a cambios de $\mathrm{pH}$ o a pH muy cercanos a la acidez, sin embargo estos trabajos deberían continuarse aunque tomando más variables que ayuden a esclarecer estos mecanismos.

\section{CONCLUSIONES}

Con base a lo anteriormente expuesto se puede considerar el uso de probióticos como una técnica verdaderamente viable, que brinda la oportunidad de producir excelentes rendimientos en cuanto a rentabilidad y calidad de los productos aumentando de esta manera los niveles de eficiencia y eficacia de las explotaciones pecuarias. 
Con el suministro de probióticos se ha podido determinar que son una alternativa viable para suplementar animales de interés zootécnico, porque facilitan la absorción de nutrientes esenciales para su desarrollo, obteniendo altos niveles de producción, encontrando así una nueva alternativa de promotor de crecimiento amigable con la salud del consumidor.

Es necesario tener los requerimientos básicos de los probióticos para cada especie ya que si este es suministrado en altas cantidades puede llegar a: acidificar tanto la luz intestinal produciendo ulceras intestinales, alta inhibición de hidrolasas lo que ocasiona un desbalance energético.

Los probióticos influyeron en la etapa de crecimiento ya que estas bacterias poseen proteasas y amilasas que rompen enlaces y facilitan su metabolismo y absorción, por lo cual los probióticos generan un crecimiento mayor en un periodo de tiempo menor, característica que lo que lo hace un promotor de crecimiento de alta calidad posibilitando la eliminación de hormonas en la producción animal.

De acuerdo con los resultados y la investigación realizada, la baja absorción de grasa es atribuida a que los probióticos hacen que el medio de la luz intestinal se torne acido, por lo tanto, la absorción de grasa se ve comprometida debido a que las enzimas lipídicas solo actúan en un medio neutro-alcalino

También un factor que pudo disparar la secreción enzimática pancreática fue el alto grado de grasas presentes en la dieta lo que a nivel intestinal forma jabones y estos también tienen un efecto positivo en la estimulación de secretina y colecistocinina incrementando la digestión de proteínas carbohidratos y grasas incrementando también los niveles de peptonas, metabolitos de proteínas que tienen efectos directos sobre la colecistocinina.

Cabe resaltar que en este trabajo no se tuvo en cuenta la digestibilidad de la dieta suministrada por tal efecto se podría sugerir otro estudio en el cual se analice si el probiótico es capaz de mejorar la digestibilidad de un alimento en 
particular, sin embargo con este trabajo podemos llegar a la conclusión que la digestibilidad mejora, de tal manera se puede usar materias primas de digestibilidad regular y ahorrar costos de alimentación muy significativos que en estas condiciones de trópico y a nivel nacional en las cuales el mayor costo de una producción es la alimentación.

Al sensibilizarse los linfocitos se estimula la producción de $\lg$ A las cuales están dispuestas cerca de la luz intestinal lo que asegura una respuesta mediata frente a cualquier entrada de patógenos a la luz intestinal, por lo que el suministro de probióticos brinda una autoinmunidad mejorada, además que la proliferación de células caliciformes hace que la secreción de mucina sea más elevada lo cual garantiza un mejor tránsito intestinal, además de pocas oportunidades a los patógenos para adherirse a las vellosidades intestinales.

Los probióticos brindan una mejor inmunidad, evitando así el uso de medicamentos xenobióticos que alteren los niveles la nuestra producción.

\section{BIBLIOGRAFÍA}

1. Aso Y., Akazan H., Kotake T., Tsukamoto T., Imai K. BLP Study Group. Preventive effect of a Lactobacillus casei preparation on the recurrence of superficial bladder cancer in a doubleblind trial. Eur Urol; 27: 104-109. 1995.

2. Barron M.P., Serrano G.C., Villarreal C., Mata B.D., Verduzco J.A., Morales M.R. Acción inhibitoria de probióticos sobre el crecimiento axenico in vitro de Entamoeba histolytica. Revista Salud Pública y Nutrición. Vol 72006.

3. De Roos N.M., Katan M.B. Effects of probiotic bacteria on diarrhea, lipid metabolism, and carcinogenesis: a review of papers published between 1988 and 1998. Am J Clin Nutr; 71: 405 - 411, 2000.

4. Djouzi Z., Andrieux C., Degivry M.C., Bouley C., Szylit O. The association of yogurt starters with Lactobacillus casei DN 114.001 in fermented milk alters the composition and metabolism of intestinal microflora in germ-free rats and in human flora-associated rats. J Nutr, 127 (2): 260 - 6. 1997.

5. Escalante L.A. El potencial de la manipulación de la flora intestinal por medios dietéticos sobre la salud humana. Enf Inf y Micro. 21: 106 - 114. 2001.

6. Fuller R. Probiotics in man and animal. J Applied Bacter 66: 365 - 78. 1989. 
7. García F., González B.E. Criterios de calidad de los microorganismos probióticos y evidencias sobre efectos hipocolesterolemicos. Revista Salud Pública y Nutrición. Vol. 7: 2006.

8. Iñiguez C., Acedo E. Mecanismos de adhesión al tracto intestinal y antagonismo de Bifidobacterium. Revista Salud Pública y Nutrición. Vol. 7: 1 10. 2006.

9. Isolauri E., Majamaa H., Arvola T., Ranmala I., Virtanen E., Arvilommi H. Lactobacillus casei strain GG reverses increased intestinal permeability induced by cow milk in suckling rats. Gastroenterology; 105: $1.643-1.650$. 1993.

10. Kaila M., Isolauri E., Soppi E., Virtanen E., Laine S., Arvilommi H. Enhancement of the circulating antibody secreting cell response in human diarrhea by a human lactobacillus strain. Pediatr Res; 32: 141 - 144. 1992.

11. Lázaro C., Carcelén F., Torres M., Ara M. Efecto de probióticos en el alimento de marranas sobre los parámetros productivos de lechones. Rev Inv Vet Peru. 16: 97 - 102. 2005.

12. Majamaa H., Isolauri E. Probiotics: A novel approach in the manegement of food allergy. J Allergy Clin Immunol; 99: 179 - 185. 1997.

13. Marteau P., Flourié B., Pochart P., Chastang C., Desjeux J.F., Rambaud J.C. Effect of the microbial lactase (EC 3.2.1.23) activity in yoghurt on the intestinal absorption of lactose: an in vivo study in lactasedeficient humans. $\mathrm{Br} \mathrm{J}$ Nutr, 64: 71 - 9. 1990.

14. Marteau P., Pochart P., Flourié B. Effect of chronic ingestion of a fermented dairy product containing Lactobacillus acidophilus and Bifidobacterium bifidum on metabolic activities of the colonic microflora. Am J Clin Nutr; 52: 685 - 688. 1990.

15. Martínez C., Mesa del Castillo M. Probióticos: ¿fantasía o realidad?. An Med Interna. 22: 53 - 54. 2005.

16. McFarland L.V. Beneficial microbes. Health or hazard? Eur Gastroenterol Hepatol; 12 (10): 1069 - 1071. 2000.

17. Miranda N.M.G. Probióticos y micronutrientes ¿son útiles para el tratamiento de la diarrea aguda?. Bol Med Hosp Infat Mex. 65: 157 - 166. 2008.

18. Mombelli B., Gismondo M.R. The use of probiotics in medical practice. Int. Antimicrob Agents; 16 (4): 531 - 536. 2000.

19. Nieto A. Prevención primaria de la alergia alimentaria - probióticos tolerancia oral. An Esp Pediatr, 126: 31 - 34. 1999.

20. Oropeza M.A., Posadas E., Cervantes J.M. Prevención de afecciones gastrointestinales mediante el uso de probióticos en becerros Holstein lactantes. Vet Mex. 29: 197 - 201. 1998. 
21.Pardio V.T., Krzysatof N., Waliszewski K.N, Robledo G. Los probióticos y su futuro. Arch Latinoam Nutr ;(4681): 6 - 10. 1994.

22. Penna F.J. Diarrea y probióticos. Simposio sobre utilidad de los probióticos en el manejo de las diarreas. Rev Enfer Infec Ped; XI (6): 182. 1998.

23. Puertollano E., Puertollano M.A., Álvarez G., Pablo M. Probióticos aspectos críticos de su eficacia sobre la salud. Actualidad Sem. 45: 28 - 33. 2008.

24. Saavedra J.M. Microbes to fight microbes: A not so novel aproach to controlling diarrheal disease. J Pediatr Gastroenterol Nutr, 21: 125 - 129. 1995.

25. Salminen S., Salminen E. Lactulose, lactic acid bacteria, intestinal rnicroecology and mucosal protection. Scand J Gastroenterol; 32 (Suppl 222): 45 - 8. 1997.

26. St-Onge M.P., Farnworth E.R., Jones P.J.M. Consumption of fermented and nonfermented dairy products: effects on cholesterol concentrations and metabolism. Am J Clin Nutr, 71: 674 - 681. 2000.

27. Sutas Y., Hurme M., Isolauri E. Down-regulation of anti-CD3 antibodyinduced IL-4 production by bovine caseins hyidrolized with Lactobacillus GGderived enzymes. Scand J Immunol; 43: 697 - 689. 1996.

28. Vallejo F., Toro M.A. Análisis microbiológico en yogurt con probióticos. Boletín Micologico. 17: 15 - 19. 2002.

29. Vanderhoof J. A., Young R. J. Use of probiotics in childhood gastrointestinal disorders. J Pediatr Gastroenterol Nutr; 27: 323 - 332. 1998.

30. Vega L. Una década de experiencia en la investigación de probióticos y prebióticos, y su aplicación en medicina. Revista Mexicana de Pediatría. 72 : 107 - 108. 2005. 